\title{
UČEŠĆE U SPORTU NAKON POVREDE PREDNJEG UKRŠTENOG LIGAMENTA
}

\author{
Bojan Ilić ${ }^{1}$, Aleksandra Nikolić ${ }^{2}$ i Dejan Ilić ${ }^{3}$ \\ ${ }^{1}$ Obrazovni sistem „Ruđer Bošković“, Beograd, Republika Srbija \\ ${ }^{2}$ Fakultet sporta i fizičkog vaspitanja, Beograd, Republika Srbija \\ ${ }^{3}$ Fakultet sporta i fizičkog vaspitanja, Beograd, Republika Srbija
}

Stručni članak

\section{SAŽETAK}

Jedan od najčěšcih problema vezanih za zglob kolena, su povrede ili ruptura prednjeg ukrštenog ligamenta. Povreda ili ruptura ACL-a, kao jednog od četiri velika ligamenta zgloba kolena, predstavlja njegovu najtežu povredu. Povrede ligamenta često dovode do preranog prekida sportske karijere kod sportista. Tretman nakon rupture ACL-a može biti operativan ili konzervativan. U oba slučaja, glavni cilj je da pacijent postigne što bolji funkcionalni nivo, bez rizika od ponovnog povređivanja ili degenerativnih povreda u zglobu kolena. Vraćanje na visok nivo sportske aktivnosti pokazatelj je uspešnog tretmana. Rehabilitacija predstavlja važan deo tretmana. Znanje o procesu izlečenja i biomehanici kolena nakon povrede $i$ rekonstrukcije, zajedno sa fiziološkim aspektima trenažnih efekata je važno za konstrukciju rehabilitacionih programa. Trenutni rehabilitacioni programi koriste neposredne treninge, tj. vežbe kojima se radi na povećanju opsega pokreta. U većini slučajeva, rehabilitacioni programi se prave u odnosu na vreme koje je potrebno za vraćanje određenim sportskim aktivnostima. U ovom članku, želeo se napraviti pregled trenutnih strategija sportske participacije $i$ rehabilitacije nakon povrede ACL-a. Operacija zajedno sa obavljenim, završenim rehabilitacionim programom, koji je specifičan za dati sport, trebalo bi da dovedu do funkcionalne stabilnosti zgloba kolena. Staviše, adekvatna mišićna jačina i performanse predstavljaju glavne kriterijume za vraćanje sportu. Drugi faktori, kao što su prateće povrede, sociološke $i$ psihološke barijere, takođe mogu uticati na vraćanje sportskim aktivnostima. Stoga, moraju se uzeti u razmatranje tokom procesa rehabilitacije i evaluacije tretmana.

Ključne reči: fizioterapija, oporavak, povreda, sportska medicina, rehabilitacija

\section{UVOD}

Vrhunski sportisti su izloženi većem riziku od povređivanja prednjeg ukrštenog ligementa (Roos, Ornell, Gardsell et al., 1995; Bjordal, Arnly, Hannestad et al., 1997). Pored toga, rizik od povređivanja je veći među ženama (Roos, Ornell, Gardsell et al., 1995; Bjordal, Arnly, Hannestad et al., 1997; Myklebust, Maehlum, Engebretsen et al., 1997; Hewett, Lindenfeld, Riccobene et al., 1999).

Povreda prednjeg ukrštenog ligementa (ACL) dovodi do statičke i funkcionalne nestabilnosti koja izaziva promene u paternima kretanja (Berchuck, Andriacchi, Bach et al., 1990; Beard, Dodd, Trundle et al., 1994; Kvist i Gillquist, 2001) i povećava rizik za oboljevanje od osteoartritisa (Gillquist i Messner, 1999).

U mnogim slučajevima povreda ACL-a dovodi do preranog okončanja sportske karijere (Roos, Ornell, Gardsell et al., 1995; Bjordal, Arnly, Hannestad et al., 1997). Studija 
(Roos, Ornell, Gardsell et al., 1995) je pokazala da je samo 30\% fubalera bilo aktivno 3 godine nakon povrede ACL-a.

Tokom operacije, nakon povrede ACL-a, pokidani ligament se zamenjuje graftom kako bi se smanjilo prekomerno anteriorno pomeranje tibije u sagitalnoj ravni. Glavni cilj rekonstrukcije je da se bezbolno povrati funkcija kolena bez ikakvih degenerativnih promena u vezi sa operacijom.

Nemoraju svi pacijenti sa sa pokidanim ACL-om da se operišu. Najčešći kriterijumi selekcije su starost pacijenta, prateće povrede ligamenata i meniskusa, funkcionalni i sportski zahtevi u odnosu na koleno, kao i spremnost ili volja pacijenta da aktivno učestvuje u postoperativnoj rehabilitaciji.

\section{Zglob kolena}

Zglob kolna je jedan od najjačih i najvažnijih zglobova u ljudskom telu. Omogućava da se potkolenica pokreće u odnosu na natkolenicu, trpeći težinu tela. Pokreti u zglobu kolena su od velike važnosti za obavljanje svakodnevnih aktivnosti kao što su: hodanje, trčanje, sedenje i stajanje.

Zglob kolena grade tri kosti: butna kost (femur), čašica (patella) i golenjača (tibia). Tetive povezuju kosti zgloba kolena sa mišićima nogu koji pokreću koleno.ligamenti spajaju kosti zgloba kolena i pružaju stabilnost kolena. Mogu se morfološki izdvojiti patelofemoralni zglob i femorotibijalni zglob sa dva odeljka, spojašnjim i unutrašnjim.

Zglob kolena je zaštićen dobro inervisanom zglobnom ovojnicom, koja se pruža proksimalno od čašične zglobne površine butne kosti (facies patellaris femoris) i formira suprapatelarni džep zgloba kolena (Fulkerson i Hungerford, 1990).

\subsection{Prednja ukrštena veza}

Prednja ukrštena veza je unutarzglobna, ali i ekstrasinovijalna zglobna struktura. ACL se proteže od široke baze na prednjoj strani golenjače pa do lateralnog kondila butne kosti, na njegovoj posteromedijalnoj strani (Micheo, Hernandez i Seda, 2010). ACL se sastoji iz dva snopa, anteromedijalnog i posterolateralnog snopa (Norwood i Cross, 1979).

Prednji ukršteni ligament je glavna kočnica prednje tibijalne translacije i sekundarna linija odbrane na sile velikog intenziteta koje deluju u pravcu nastanka varus i valgus deformiteta (Ninković, 2011).

Svi ligamenti, pa tako i ukršteni, poput tetiva mišića imaju građu koja nastaje usled sila koje deluju na njih. Tetive i ligamenti imaju sposobnost adaptacije svoje morfologije usled promena u njihovom mehaničkom okruženju koje mogu nastati nakon povrede, bolesti ili treninga.

Anatomija ACL-a je od velikog značaja u procesu rehabilitacije i rekonstrukcije. Prikladna rekonstrukcija i sveobuhvatan oporavak omogućavaju da rekonstruisani ACL vremenom poprimi što više od svoje prvobitne anatomije što kasnije dovodi do poboljšanja funkcionalnosti (Markatos, Kaseta, Lallos, Korres i Efstathopoulos, 2013).

\section{Tretman nakon povrede ACL-a i način bezbednog vraćanja sportu}

Glavni razlog zbog koga je bitno obaviti rehabilitaciju nakon povrede ACL-a je postizanje dobre funkcionalne stabilnosti, zatim postizanje najboljeg mogućeg funkcionalnog nivoa kao i smanjenje rizika od ponovnog povređivanja. Trenažni programi su fokusirani i na povređenu i na zdravu nogu, zatim na mišiće kuka i trupa koji su potrebni za stabilizaciju celog tela.

Funkcionalna stabilnost zgloba kolena je zavisna od uzajamnog dejstva pasivnih struktura i dinamičkog sistema. Ona je takođe u zavisnosti od koordinacije i propriocepcije. Deficit mišićne sile (Muellner, Alacamlioglu, Nikolić et al., 1998; Osteras, Augestad i 
Tondel, 1998; Risberg, Holm, Tjomsland et al., 1999a; Risberg, Holm, Steen et al., 1999b; Mikkelsen, Werner i Eriksson, 2000; Henriksson, Rockborn i Good 2002; Keays, BullockSaxton, Newcombe et al., 2003) i propriocepcije (Friden, Roberts, Ageberg et al., 2001) može se zapaziti nakon povrede ACL-a.

\subsection{Neuromuskularni trening}

Neuromuskularni trening ima za cilj poboljšanje sposobnosti nervnog sitema da generiše brzu i optimalnu mišićnu kontrakciju, zatim poboljšanje koordinacije i ravnoteže, kao i ponovno učenje određenih veština i paterna pokreta (Risberg, Mork, Jenssen et al., 2001). Važnost neuromuskularnog treninga pokazana je u prospektivnim kontrolnim studijama gde je incidenca povređivanja ACL-a bila znatno niža kod sportista koji su upražnjavali proprioceptivni trening (Caraffa, Cerulli, Projetti et al., 1996; Hewett, Lindenfeld, Riccobene et al., 1999).

Vežbe zatvorenog kinetičkog lanca su postale jako popularne i vrlo često se preporučuju u rehabilitaciji nakon povrede ACL-a jer se veruje da su bezbednije u odnosu na druge vežbe (Shelbourne i Nitz, 1990; Palmitier, An, Scott et al., 1991; Bynum, Barrack i Alexander 1995; Panni, Milano, Tartarone et al., 2001; Henriksson, Rockborn i Good 2002; Pinczewski, Deehan, Salmon et al., 2002; Jansson, Linko, Sandelin et al., 2003).

Međutim, idalje nemamo dokaze koji bi podržali takvo stanovište (Beynnon i Johnson, 1996; Fitzgerald, Axe i Snyder-Mackler, 2000; Morrissey, Hudson, Drechsler et al., 2000; Mikkelsen, Werner i Eriksson 2000).

\subsection{Opseg pokreta}

Većina autora je otpočela trening opsega pokreta odmah nakon operacije. Rana postoperativna mobilizacija kolena eliminiše štetne efekte imobilizacije na stegnutost grafta i kasniju silu kolena. Proteze limitiraju opseg pokreta, a u nekim slučajevima sprečavaju anteriorno-posteriornu translaciju. Nisu primećeni korisni efekti kada se proteza za koleno koristila tokom prvih 6 nedelja nakon operacije (Nielsen i Yde 1991; Feller, Bartlett, Chapman et al., 1997; Kartus, Stener, Kohler et al., 1997; Muellner, Alacamlioglu, Nikolić et al., 1998; Möller, Forssblad, Hansson et al., 2001).

\subsection{Pun oslonac na noge}

U 21 od 34 pregledanih članaka, oslonac na noge je bio dozvoljen odmah nakon operacije u zavisnosti od bola, otoka u zglobu kolena i od stepena gubitka ekstenzije.

Efekat ranog oslanjanja na labavost kolena još uvek nije temeljno ispitan. (Tyler, McHugh, Gleim et al., 1998) su poredili pacijente koji su odmah nakon operacije počeli sa oslanjanjem na nogu i one koji su to počeli tek 2 sedmice nakon operacije. Nakon 7 meseci praćenja nisu našli razlike između ove dve grupe pacijenata.

\section{Kada se sportisti mogu vratiti laganim i kontaktnim sportskim aktivnostima?}

Odluka o tome kada se pacijentu može odobriti vraćanje normalnim aktivnostima i sportu, u većini slučajeva zavisi od iskustva. Nepotrebno odlaganje povratka normalnim aktivnostima ili sportu je nepoželjno isto kao i prerano vraćanje jer može doći do povrede grafta.

U studijama koje smo pregledali, pacijentima se obično dozvoljavalo da se vrate laganim aktivnostima, kao što je to trčanje, već 2-3 meseca nakon operacije, a kontaktnim sportovima nakon 6 meseci. Bitno je ispitati jačinu mišića i nivo performansi 6 meseci nakon operacije jer se obično tada većina pacijenata vraća kontaktnim sportovima.

Prema IKDC-u (International Knee Documentation Committee) deficit koji je manji od $10 \%$, u testu skoka udalj sa jedne noge, ukazuje na normalno funkcionisanje kolena. Naravno, ova ograničenja se moraju uzeti u razmatranje zajedno sa drugim kriterijumima za 
vraćanje sportskim aktivnostima, kao što su: asimptomatično koleno (bez bola ili oticanja, pun opseg pokreta), zatim prateće povrede i psihološki faktori (Morrey, Stuart, Smith et al., 1999; Risberg, Holm, Steen et al., 1999a; Shelbourne i Davis, 1999; Ross, Irrgang, Denegar et al., 2002).

Iz prethodnih tvrdnji možemo zaključiti da se sportisti mogu vratiti sportskim aktivnostima samo pod odobrenjem i nadzorom od strane svog lekara. Ukoliko je to moguće, poželjno je da sportista blisko sarađuje sa sertifikovanim sportskim trenerom svog tima.

\section{Preporuke za vraćanje sportskim aktivnostima}

Jedna od glavnih indikacija za rekonstrukciju ACL-a je ta što pacijentu dozvoljava povratak sportskim aktivnostima (Webb, Corry, Clingeleffer et al., 1998). Pored toga, stopa vraćanja sportskim aktivnostima na vrhunskom nivou indikator je uspešno obavljene rekonstrukcije ACL-a (Deehan, Salmon, Webb et al., 2000).

Međutim, postavlja se pitanje „Da li je jedini cilj rekonstrukcije ACL-a da se sportisti da dovoljno sigurnosti kako bi obavljao aktivnosti visokog inteziteta dok može, a da potom upropasti koleno?“(Gillquist i Messner, 1999).

Kako bi se pacijent vratio sportskim aktivnostima, rehabilitacija mora biti izvršena u skladu sa zahtevima koje smo izložili u figuri 1. ovog teksta.

Figura 1. Faktori i kriterijumi koji utiču na bezbedan povratak sportskim aktivnostima.

\begin{tabular}{|c|c|c|c|c|}
\hline \multirow{3}{*}{ 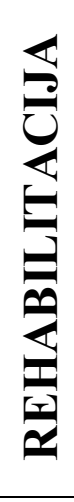 } & $\begin{array}{l}\text { Mišićna sila i performanse } \\
\text { (izokinetički test } \mathrm{i} \text { test } \\
\text { skočnosti sa jedne noge; }<10- \\
15 \% \text { deficit). }\end{array}$ & \multirow{2}{*}{$\begin{array}{l}\text { BEZBEDAN } \\
\text { POVRATAK } \\
\text { SPORTU }\end{array}$} & $\begin{array}{l}\text { Socijalni faktori (porodica, } \\
\text { trudnoća, studije itd.) }\end{array}$ & \multirow{3}{*}{ 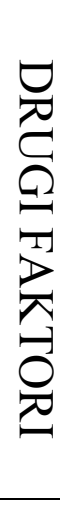 } \\
\hline & $\begin{array}{l}\text { Bez bola ili otoka; pun opseg } \\
\text { pokreta (kliničko ispitivanje). }\end{array}$ & & $\begin{array}{c}\text { Psihološki faktori } \\
\text { (motivacija, školarina, strah } \\
\text { od ponovnog povređivanja } \\
\text { itd). }\end{array}$ & \\
\hline & $\begin{array}{c}\text { F-na stabilnost kolena } \\
\text { (kliničko ispitivanje, } \\
\text { objektivne mere-analiza } \\
\text { pokreta). }\end{array}$ & $\begin{array}{c}\text { Statička stabilnost } \\
\text { kolena (kliničko } \\
\text { ispitivanje, objektivne } \\
\text { mere-KT1000). } \\
\end{array}$ & $\begin{array}{c}\text { Pridružene povrede } \\
\text { (meniskusa, hrskavice, drugih } \\
\text { ligamenata itd.) }\end{array}$ & \\
\hline & \multicolumn{3}{|c|}{ OPERACIJA } & \\
\hline
\end{tabular}

\section{ZAKLJUČAK}

Trend u rehabilitaciji nakon povrede ACL-a podrazumeva ubrzavanje celog procesa oporavka. Pored toga, vraćanje sportskim aktivnostima često se smatra indikatorom uspešnog tretmana. Međutim, moraju se uzeti u razmatranje pitanja da li je bezbedno da se sportista vrati svojim aktivnostima, kao i to zašto je neki sportista odustao od svoje sportske karijere.

Cilj rekonstrukcije ACL-a je poboljšanje stabilnosti kolena mada dešava se da čak i nakon te operacije, sagitalna translacija bude povećana. Štaviše, ovo nije koreliralo sa funkcionisanjem kolena kao ni sa vraćanjem sportskim aktivnostima. Mnogi pacijenti mogu da aktivno učestvuju u sportu i pored velike razlike u sagitalnoj translaciji između operisane i zdrave noge što ističe važnost funkcionalne stabilnosti i dobre mišićne funkcije.

$\mathrm{Na}$ osnovu trenutnog znanja i komplijanse pacijenta, potrebno je ispuniti određene kriterijume kako bi se dozvolio povratak sportskim aktivnostima. Neki od tih kriterijuma su: završena rehabilitacija, adekvatna mišićna sila, zatim performanse koje su na zadovoljavajućem nivou, kao i funkcionalna stabilnost kolena. 
Operacija treba da rezultira stabilnošću kolena što se da proceniti statičkim merenjem sagitalne translacije. Drugi faktori, kao što su prateće povrede, socijalne i psihološke barijere, mogu uticati na vraćanje sportskim aktivnostima.

\section{LITERATURA}

Beard, D.J., Dodd, C.A., Trundle, H.R. et al. (1994). Proprioception enhancement for anterior cruciate ligament deficiency: a prospective randomised trial of two physiotherapy regimes. J Bone Joint Surg Br, 76(4), 654-659.

Berchuck, M., Andriacchi, T.P., Bach, B.R. et al. (1990). Gait adaptations by patients who have a deficient anterior cruciate ligament. J Bone Joint Surg Am, 72(6), 871-877.

Beynnon, B.D. \& Johnson, R.J. (1996). Anterior cruciate ligament injury rehabilitation in athletes: biomechanical considerations. Sports Med, 22(1), 54-64.

Bjordal, J.M., Arnly, F., Hannestad, B. et al. (1997). Epidemiology of anterior cruciate ligament injuries in soccer. Am J Sports Med, 25(3), 341-345.

Bynum, E.B., Barrack, R.L. \& Alexander, A.H. (1995). Open versus closed chain kinetic exercises after anterior cruciate ligament reconstruction: a prospective randomized study. Am J Sports Med, 23(4), 401-406.

Caraffa, A., Cerulli, G., Projetti, M. et al. (1996). Prevention of anterior cruciate ligament injuries in soccer: a prospective controlled study of proprioceptive training. Knee Surg Sports Traumatol Arthrosc, 4(1), 19-21.

Deehan, D.J., Salmon, L.J., Webb, V.J. et al. (2000). Endoscopic reconstruction of the anterior cruciate ligament with an ipsilateral patellar tendon autograft: a prospective longitudinal five-year study. J Bone Joint Surg Br, 82(7), 984-991.

Feller, J., Bartlett, J., Chapman, S., et al. (1997). Use of an extension-assisting brace following anterior cruciate ligament reconstruction. Knee Surg Sports Traumatol Arthrosc, 5(1), 6-9.

Fitzgerald, G.K., Axe, M.J. \& Snyder-Mackler, L. (2000). The efficacy of perturbation training in nonoperative anterior cruciate ligament rehabilitation programs for physical active individuals. Phys Ther, 80(2), 128-140.

Friden, T., Roberts, D., Ageberg, E. et al. (2001). Review of knee proprioception and the relation to extremity function after an anterior cruciate ligament rupture. J Orthop Sports Phys Ther, 31(10), 567-576.

Fulkerson, J. \& Hungerford, D. (1990). Normal anatomy. In Disordersof the Patellofemoral Joint. Baltimore, USA.

Gillquist, J. \& Messner, K. (1999). Anterior cruciate ligament reconstruction and the longterm incidence of gonarthrosis. Sports Med, 27(3), 143-156.

Henriksson, M., Rockborn, P. \& Good, L. (2002). Range of motion training in brace vs plaster immobilization after anterior cruciate ligament reconstruction: a prospective randomized comparison with a 2-year follow-up. Scand J Med Sci Sports, 12(2), 7380.

Hewett, T.E., Lindenfeld, T.N., Riccobene, J.V. et al. (1999). The effect of neuromuscular training on the incidence of knee injury in female athletes: a prospective study. $\mathrm{Am} \mathrm{J}$ Sports Med, 27(6), 699-706.

Jansson, K.A., Linko, E., Sandelin, J. et al. (2003). A prospective randomized study of patellar versus hamstring tendon autografts for anterior cruciate ligament reconstruction. Am J Sports Med, 31(1), 12-18.

Kartus, J., Stener, S., Kohler, K. et al. (1997). Is bracing after anterior cruciate ligament reconstruction necessary?: a 2-year follow-up of 78 consecutive patients 
rehabilitated with or without a brace. Knee Surg Sports Traumatol Arthrosc, 5(3), 157-161.

Keays, S.L., Bullock-Saxton, J.E., Newcombe, P. et al. (2003). The relationship between knee strength and functional stability before and after anterior cruciate ligament reconstruction. J Orthop Res,21(2), 231-237.

Kvist, J. \& Gillquist, J. (2001). Anterior positioning of tibia during motion after anterior cruciate ligament injury. Med Sci Sports Exerc, 33(7), 1063-1072.

Markatos, K., Kaseta, M.K., Lallos, S.N., Korres, D.S. \& Efstathopoulos, N. (2013). The anatomy of the ACL and its importance in ACL reconstruction. Eur J Orthop Surg Traumatol., 23(7), 747-752.

Mikkelsen, C., Werner, S. \& Eriksson, E. (2000). Closed kinetic chain alone compared to combined open and closed kinetic chain exercises for quadriceps strengthening after anterior cruciate ligament reconstruction with respect to return to sports: a prospective matched follow-up study. Knee Surg Sports Traumatol Arthrosc, 8(6), 337-342.

Micheo, W., Hernandez, L. \& Seda, C. (2010). Evaluation, management, rehabilitation, and prevention of anterior cruciate ligament injury: current concepts. PM R., 2(10), 935944.

Möller, E., Forssblad, M., Hansson, L. et al. (2001). Bracing versus nonbracing in rehabilitation after anterior cruciate ligament reconstruction: a randomized prospective study with 2-year follow-up. Knee Surg Sports Traumatol Arthrosc, 9(2), 102-108.

Morrey, M.A., Stuart, M.J., Smith, A.M. et al. (1999). A longitudinal examination of athletes' emotional and cognitive responses to anterior cruciate ligament injury. Clin J Sport Med, 9(2), 63-69.

Morrissey, M.C., Hudson, Z.L., Drechsler, W.I. et al. (2000). Effects of open versus closed kinetic chain training on knee laxity in the early period after anterior cruciate ligament reconstruction. Knee Surg Sports Traumatol Arthrosc, 8(6), 343-348.

Muellner, T., Alacamlioglu, Y., Nikolic, A. et al. (1998). No benefit of bracing on the early outcome after anterior cruciate ligament reconstruction. Knee Surg Sports Traumatol Arthrosc, 6(2), 88-92.

Myklebust, G., Maehlum, S., Engebretsen, L. et al. (1997). Registration of cruciate ligament injuries in Norwegian top level team handball: a prospective study covering two seasons. Scand J Med Sci Sports, 7(5), 289-292.

Nielsen, A.B. \& Yde, J. (1991). Epidemiology of acute knee injuries: a prospective hospital investigation. J Trauma, 31(12), 1644-1648.

Ninković S. (2011). Uvećanje koštanog kanala u butnoj kosti i golenjači nakon rekonstrukcije prednjeg ukrštenog ligamenta kolena. Doktroska disertacija, Univerzitet u Novom Sadu, Medicinski fakultet Novi Sad.

Norwood, L. \& Cross, M. (1979). Anterior cruciate ligament: functional anatomy of its bundles in rotatory instabilities. Am J Sports Med., (7), 23-26.

Osteras, H., Augestad, L.B. \& Tondel, S. (1998). Isokinetic muscle strength after anterior cruciate ligament reconstruction. Scand J Med Sci Sport, 8 (5), 279-282.

Palmitier, R.A., An, K.N., Scott, S.G. et al. (1991). Kinetic chain exercise in knee rehabilitation. Sports Med, 11(6), 402-413.

Panni, A.S., Milano, G., Tartarone, M. et al. (2001). Clinical and radiographic results of ACL reconstruction: a 5- to 7-year follow-up study of outside-in versus inside-out reconstruction techniques. Knee Surg Sports Traumatol Arthrosc; 9(2), 77-85. 
Pinczewski, L.A., Deehan, D.J., Salmon, L.J. et al. (2002). A five-year comparison of patellar tendon versus four-strand hamstring tendon autograft for arthroscopic reconstruction of the anterior cruciate ligament. Am J Sports Med, 30(4), 523-536.

Risberg, M.A., Holm, I., Steen, H. et al. (1999a). The effect of knee bracing after anterior cruciate ligament reconstruction: a prospective, randomized study with two years' follow-up. Am J Sports Med, 27(1), 76-83.

Risberg, M.A., Holm, I., Tjomsland, O. et al. (1999b). Prospective study of changes in impairments and disabilities after anterior cruciate ligament reconstruction. J Orthop Sports Phys Ther, 29(7), 400-412.

Risberg, M.A., Mork, M., Jenssen, H.K. et al. (2001). Design and implementation of a neuromuscular training program following anterior cruciate ligament reconstruction. J Orthop Sports Phys Ther., 31(11), 620-631.

Roos, H., Ornell, M., Gardsell, P. et al. (1995). Soccer after anterior cruciate ligament injury: an incompatible combination?: a national survey of incidence and risk factors and a 7-year follow-up of 310 players. Acta Orthop Scand, 66(2), 107-112.

Ross, M.D., Irrgang, J.J., Denegar, C.R. et al. (2002). The relationship between participation restrictions and selected clinical measures following anterior cruciate ligament reconstruction. Knee Surg Sports Traumatol Arthrosc, 10(1), 10-19.

Shelbourne, K.D. \& Davis, T.J. (1999). Evaluation of knee stability before and after participation in a functional sports agility program during rehabilitation after anterior cruciate ligament reconstruction. Am J Sports Med, 27(2), 156-161.

Shelbourne, K.D. \& Nitz, P. (1990). Accelerated rehabilitation after anterior cruciate ligament reconstruction. Am J Sports Med., 18(3), 292-299.

Tyler, T., McHugh, M., Gleim, G. et al. (1998). The effect of immediate weightbearing after anterior cruciate ligament reconstruction. Clin Orthop., (357), 141-148.

Webb, J.M., Corry, I.S., Clingeleffer, A.J. et al. (1998). Endoscopic reconstruction for isolated anterior cruciate ligament rupture. J Bone Joint Surg Br., 80(2), 288-294.

Primljeno: 04.05.2017.

Odobreno: 26.06.2017.

Korespodencija:

Prof. dr Dejan Ilić

Fakultet sporta i fizičkog vaspitanja

Univerzitet u Beogradu

Blagoja Parovića 156

11030 Beograd

Srbija

Tel:+381(11)3531-000

dejan.ilic@fsff.bg.ac.rs 